https://doi.org/10.1590/198053145305

\title{
CLIMA ESCOLAR COMO FATOR PROTETIVO AO DESEMPENHO EM CONDIÇÕES SOCIOECONÔMICAS DESFAVORÁVEIS'
}

\author{
Simone Gomes de Melo' \\ Alessandra de Morais"
}

\section{Resumo}

O objetivo deste estudo é verificar a relação entre clima escolar e desempenho em escolas públicas de ensino médio representativas de um estado brasileiro, a partir da percepção de alunos, professores e gestores. O clima escolar foi avaliado por meio de questionários compostos por oito dimensões. Já o desempenho foi analisado com dados do Exame Nacional do Ensino Médio (Enem) 2015. Participaram da pesquisa 2.731 alunos, 426 professores e 173 gestores de uma amostra de 46 escolas, representativa de um estado brasileiro. Os resultados indicaram uma relação de mesmo sentido entre o clima escolar e o desempenho por meio da análise do efeito escola ao controlar o indicador de nível socioeconômico, demonstrando que o clima escolar agiu como fator protetivo para a conquista de um melhor desempenho acadêmico.

\section{AMBIENTE ESCOLAR • RENDIMENTO ESCOLAR • ENSINO MÉDIO • \\ EXAME NACIONAL DO ENSINO MÉDIO, ENEM}

\section{SCHOOL CLIMATE AS A PROTECTIVE FACTOR OF SCHOOL PERFORMANCE IN UNFAVORABLE SOCIOECONOMIC CONDITIONS \\ Abstract}

The purpose of this study is to verify the relationship between school climate and performance in public high schools representative of a Brazilian state, based on the perceptions of students, teachers and managers. The school climate was evaluated using questionnaires covering eight dimensions. However, the performance was based on results of the 2015 ENEM. 2731 students, 426 teachers and 173 managers from 46 schools representative of a Brazilian state participated in the survey. The results of the analysis of the school effect, controlling for the socioeconomic level indicator variable, showed a positive relationship between climate and performance, demonstrating that the school climate acted as a protective factor to achieve better academic performance.

\section{SCHOOL ENVIRONMENT • SCHOOL PERFORMANCE • HIGH SCHOOL • EXAME NACIONAL DO ENSINO MÉDIO, ENEM}

1 Esta pesquisa recebeu apoio financeiro da Coordenação de Aperfeiçoamento de Pessoal de Nível Superior (Capes).

I Universidade Estadual Paulista "Júlio de Mesquita Filho" (Unesp), Marília (SP), Brasil; https://orcid.org/0000-0001-5632-7211; simone_ped@yahoo.com.br

II Universidade Estadual Paulista “Júlio de Mesquita Filho" (Unesp), Marília (SP), Brasil; https://orcid.org/0000-0001-5521-9307; alemorais.shimizu@gmail.com 


\section{CLIMAT SCOLAIRE COMME FACTEUR DE PROTECTION DE LA PERFORMANCE DANS DES MILIEUX SOCIO-ÉCONOMIQUES DÉFAVORISÉS}

\section{Résumé}

L'objectif de cette étude est de vérifier la relation entre le climat scolaire et la performance dans des lycées publics représentatifs d'un département brésilien, à partir de la perception non seulement des élèves, mais aussi des enseignants et des administrateurs. Le climat scolaire a été évalué par moyen de questionnaires comprenant huit dimensions. La performance a, quant à elle, été analysée en utilisant des données de l'Exame Nacional do Ensino Médio (ENEM), de l'année 2015. 2731 élèves ont participé à cette recherche, ainsi que 426 professeurs et 173 gestionnaires, distribués sur 46 lycées d'un département brésilien. Les résultats ont montré qu'il existait un rapport positif entre le climat scolaire et la performance à travers l'analyse de l'effet école quand la variable de l'indicateur du niveau socio-économique est contrôlée. Cela indique que le climat scolaire a agi comme un facteur protecteur pour l'amélioration de la performance scolaire.

\section{ENVIRONNEMENT SCOLAIRE • REVENU SCOLAIRE • LYCÉE • EXAME NACIONAL DO ENSINO MÉDIO, ENEM}

\section{CLIMA ESCOLAR COMO FACTOR PROTECTOR DEL RENDIMIENTO EN CONDICIONES SOCIOECONÓMICAS DESFAVORABLES}

\section{Resumen}

El objetivo de este estudio es verificar la relación entre clima escolar y rendimiento en escuelas públicas de enseñanza media representativas de un estado brasileño, a partir de la percepción de alumnos, profesores y gestores. El clima escolar fue evaluado por medio de cuestionarios compuestos por ocho dimensiones. El desempeño fue analizado con datos del Examen Nacional de la Enseñanza Media (Enem) 2015. Participaron de la investigación 2.731 alumnos, 426 profesores y 173 gestores de 46 escuelas de un estado brasileño. Los resultados indicaron una relación del mismo sentido entre el clima escolar y el rendimiento por medio del análisis del efecto escolar al controlar el indicador de nivel socioeconómico, demostrando que el clima escolar actuó como factor protector para la conquista de un mejor rendimiento académico.

\section{AMBIENTE ESCOLAR • RENDIMIENTO ESCOLAR • ENSEÑANZA MEDIA • \\ EXAME NACIONAL DO ENSINO MÉDIO, ENEM}


LUNOS, PROFESSORES, GESTORES, FUNCIONÁRIOS E, DE CERTA MANEIRA, FAMILIARES passam grande parte do seu tempo no ambiente escolar. Portanto, refletir sobre como se apresenta esse espaço é considerar a vivência de diferentes atores que compõem a comunidade escolar, ou seja, é um respeito aos membros que fazem parte dela. Além disso e não menos importante, a qualidade da educação é o objetivo não apenas desse público, mas também da sociedade em geral, que será a primeira a se beneficiar de uma educação com excelência, tanto nos aspectos intelectuais quanto nos relacionais.

Há uma concordância entre pesquisadores (SUMMER, 2006; TAYLOR, 2008; THAPA et al., 2013; CANGUÇU, 2015) de que o clima escolar se constitui de percepções e expectativas compartilhadas pelos membros da comunidade escolar sobre os diferentes aspectos (dimensões) da instituição. Porém, na abordagem das dimensões, existe uma polissemia, isto é, uma variedade no trato dos temas que serão retratados no clima escolar, o que se verifica quer no âmbito da quantidade, envolvendo duas, três ou até dez dimensões, quer no âmbito da qualidade, abrangendo temas ora mais ligados ao clima relacional - relação aluno-aluno, professor-aluno, professor-gestor -, ora mais ao organizacional - gestão educacional (BERKOWITZ et al., 2016).

Estudos mostram que um clima escolar positivo gera efeitos na segurança e prevenção ao bullying (SUMMER, 2006; THAPA et al., 2013), diante de conflitos inter-relacionais (MATTINGLY, 2007; CANGUÇU, 2015) e, não diferentemente, 
proporciona melhor desempenho acadêmico (TAYLOR, 2008; THAPA et al., 2013). Acerca dos reflexos no desempenho, a literatura aponta que as dimensões que mais se associam são: as relações com o ensino e com a aprendizagem (MA; KLINGER, 2000; SUMMER, 2006; TAYLOR, 2008; CANGUÇU, 2015); dimensão das regras, sanções e segurança na escola (SUMMER, 2006; TAYLOR, 2008; CANDIAN; RESENDE, 2013; CANGUÇU, 2015); e dimensão sobre relações sociais e os conflitos na escola (TAYLOR, 2008; CANGUÇU, 2015).

Além disso, pesquisadores têm relatado que o clima positivo é aquele no qual os atores da comunidade escolar se envolvem nas tomadas de decisão perante a escola, privilegiando uma boa explicação do professor, bom relacionamento professor-aluno, envolvimento e disciplina do professor, ao passar e corrigir lições de casa, tudo em uma atmosfera organizada, livre de ameaças e danos físicos. O clima abarca diferentes aspectos em que se favorece o sentimento de que aquela escola é boa para estudar. Pais compreendem e apoiam a missão básica da escola, tendo a oportunidade de desempenhar um papel importante em ajudar a alcançar essa missão (SUMMER, 2006; CANGUÇU, 2015).

O ambiente livre de outras preocupações, desde a infraestrutura física até as relações sociais amistosas ocorridas naquele espaço, favoreceria uma melhor disponibilidade para estudar, aprender e, consequentemente, obter melhor desempenho em avaliações. Trata-se de uma atmosfera que estimula a aprendizagem, em que alunos, professores e gestores querem passar a maior parte do dia, realizando atividades, proporcionando conhecimento e incentivando o senso de comunidade, o que também minimiza problemas relacionados ao comportamento. Portanto, tais pesquisas revelam a relação positiva entre clima escolar e melhor desempenho acadêmico (GOTTFREDSON et al., 2005; PERKINS, 2006, 2007, 2008; ROBERTS, 2007; THAPA et al., 2013).

Uma recente revisão de literatura (BERKOWITZ et al., 2016) envolvendo as questões de clima escolar, desempenho acadêmico e questões contextuais apontou que os maiores preditores de desempenho são os contextos socioeconômicos dos estudantes, ou seja, uma condição socioeconômica desfavorável tende a se corresponder com desempenhos acadêmicos baixos. Porém, diante dessa situação, qual a função do clima escolar para o alcance de resultados mais positivos em testes acadêmicos?

Impulsionados por essa questão, pesquisadores vêm se dedicando a pensar fatores que poderiam contribuir para minimizar os efeitos de condições socioeconômicas desfavoráveis sobre o desempenho acadêmico. As pesquisas têm revelado que o clima escolar é fator importante, funcionando como atenuador da quase correspondência entre baixo nível socioeconômico e baixo desempenho acadêmico, isto é, escolas com bom clima escolar têm demonstrado que conseguem obter melhor desempenho escolar, mesmo mediante um contexto desfavorável (MA; KLINGER, 2000; BRAULT, 2004; TAYLOR, 2008; CANDIAN; RESENDE, 2013).

Berkowitz et al. (2016) partilham dessa constatação, em sua revisão de literatura, na qual abordam pesquisas sobre a relação clima escolar e desempenho do aluno, frente às barreiras socioeconômicas. Segundo os autores, um clima 
positivo suaviza o efeito negativo do nível socioeconômico no desempenho acadêmico, sendo um fator protetivo e de grande potencial de contribuição para que escolas partilhem de um ambiente agradável, prazeroso, bem como alcancem melhor desempenho escolar. No entanto, de acordo com os autores, apesar de pesquisadores e educadores afiançarem a existência dessas relações, tais estudos ainda não são conclusivos em termos de evidências científicas, uma vez que, não obstante a boa qualidade dessas investigações, poucas empregam métodos de inferência a partir de um plano estatístico de tratamento de dados, de modo a confirmarem relações causais entre as variáveis investigadas. Os autores ainda assinalam para a necessidade e importância de mais pesquisas com o intuito de elaborar uma definição comum de clima escolar que contribuam para a construção e/ou uso de instrumentos confiáveis, os quais possam ser traduzidos em práticas e políticas de melhoria nas escolas, levando em conta o desempenho acadêmico e as desigualdades sociais.

Atento a esse propósito, o presente artigo tem por objetivo verificar a relação entre clima escolar - a partir da percepção de alunos, professores e gestores de escolas públicas de ensino médio representativas de um estado brasileiro - e o desempenho dessas escolas e de seus alunos. Além disso, pretende-se examinar se o clima escolar, com suas dimensões, seria um fator protetivo para o desempenho, em especial em escolas inseridas em contextos socioeconômicos desfavoráveis.

O tema escolhido se justifica pela escassez de pesquisas sobre avaliação de clima escolar, envolvendo instrumentos validados e investigando oito dimensões que contemplam diferentes aspectos do cotidiano das escolas, abrangendo aprendizagem, relações interpessoais, segurança, justiça, regras, participação da família, infraestrutura, pertencimento, relações com o trabalho e gestão. Além disso, inclui-se a percepção de diferentes membros da comunidade escolar - alunos, professores e gestores -, diferentemente de estudos que têm se reportado prioritariamente à avaliação do clima por parte dos alunos e se referindo, principalmente, ao clima relacional.

\section{MÉTODO}

Trata-se de uma pesquisa que se caracteriza pela descrição das comunidades escolares nos papéis de aluno, professor e gestor com o auxílio de determinadas variáveis, como o clima escolar e o desempenho dessas escolas, mediante dados contextuais, de acordo com avaliação externa. Ainda, ressalta-se a intenção de se aproximar do nível explicativo, visto que, na medida do possível, procura-se investigar a natureza dessas relações (GIL, 2010, 2012). No que concerne à natureza dos dados, a pesquisa configura-se de modo quantitativo e correlacional. Quanto às questões éticas, foi obtida aprovação do Comitê de Ética em Pesquisa, recebendo parecer favorável (CAAE: 32973114.2.0000.5404). 


\section{AMOSTRA}

A amostra foi extraída de um banco de dados do projeto Em busca de caminhos que promovam a convivência respeitosa em sala de aula todos os dias: investigando o clima escolar, ${ }^{2}$ cuja coleta foi realizada por uma equipe de pesquisadores, da qual as autoras deste artigo participam. Na seleção das escolas que compuseram o universo desta pesquisa, utilizaram-se os seguintes requisitos: ser de natureza pública; oferecer ensino médio; ter passado por uma avaliação de clima escolar e ter seus dados de desempenho no Exame Nacional do Ensino Médio (Enem) 2015 divulgados publicamente.

Diante desse filtro, obteve-se um conjunto de escolas de um determinado estado do Brasil, cuja escolha se deu por conveniência devido a uma parceria entre o Instituto Unibanco e a equipe da pesquisa supracitada, de modo que o primeiro utilizou os instrumentos de avaliação de clima para analisar os efeitos de um determinado programa em escolas públicas de ensino médio; em contrapartida, foi disponibilizado o banco de dados da coleta. Ressalta-se que o estudo não permite uma generalização para o país, restringindo-se a interpretação dos resultados e possíveis inferências ao estado objeto da coleta. O desenho da seleção amostral foi aplicado ao conjunto das escolas estaduais de ensino médio, de todo o estado participante, que tivessem no mínimo 120 alunos matriculados, totalizando 221 escolas. Respeitando os critérios já elencados e a proporção de escolas em diferentes regiões do estado em questão, extraiu-se uma amostra aleatória de 46 escolas.

A seleção dos alunos, professores e gestores de cada escola ocorreu da seguinte forma: com relação aos alunos, cada turma participante, de cada escola selecionada, foi escolhida de modo aleatório, procurando-se atingir o total de 50 alunos por escola; quanto aos docentes, procurou-se selecioná-los também de maneira aleatória, sendo sorteados dez docentes por escola, que atuassem em ao menos uma turma de ensino médio; e no referente à equipe gestora, todos os profissionais disponíveis na escola, no momento da realização da pesquisa, foram convidados a participar.

Assim, na avaliação do clima escolar, a coleta envolveu alunos do $1^{\circ}$ ao $3^{\circ}$ ano do ensino médio, assim como seus professores e gestores (diretor, vice-diretor, coordenador, orientador, supervisor), abrangendo 2.731 alunos, 426 professores e 173 gestores, num total de 3.330 participantes. Já para avaliação de desempenho, participaram 46 escolas em que esses alunos, professores e gestores se inseriam, sendo utilizada, para tanto, a nota do Enem 2015.

\section{INSTRUMENTOS DE AVALIAÇÃO DO CLIMA E DE DESEMPENHO}

Empregaram-se questionários sobre o clima escolar para serem respondidos por alunos, professores e gestores das 46 escolas da amostra investigada.

2 Trata-se de um projeto interinstitucional que visou construir, testar e validar três instrumentos, adaptados à realidade das escolas brasileiras, para avaliar o clima escolar em alunos do $7^{\circ}$ ao $9^{\circ}$ ano, docentes e gestores. Coordenado pelas professoras Dra. Telma Vinha (Unicamp) e Dra. Alessandra de Morais (Unesp), o projeto contou com a equipe de pesquisadores do Grupo de Estudos e Pesquisas em Educação

Moral (Gepem) e de diversas instituições, sendo financiado pela Fapesp e Fundação Lemann. 
Quanto ao desempenho, as informações foram obtidas no site do Instituto Nacional de Estudos e Pesquisas Educacionais Anísio Teixeira (Inep), ${ }^{3}$ analisando-se os resultados brutos do Enem, juntamente com dados de contexto de cada escola. Por fim, foi realizada uma análise contextual, utilizando-se o efeito escola, nessa categoria.

\section{Clima escolar}

Os questionários voltados para alunos, professores e gestores contam com oito dimensões, as quais contemplam questões da realidade das escolas brasileiras, a saber: relações com o ensino e com a aprendizagem (Dimensão 1); relações sociais e conflitos na escola (Dimensão 2); regras, sanções e segurança na escola (Dimensão 3); situações de intimidação entre alunos (Dimensão 4); família, escola e comunidade (Dimensão 5); infraestrutura e rede física da escola (Dimensão 6); relações com o trabalho (Dimensão 7); e gestão e participação (Dimensão 8). No Quadro 1, enuncia-se o que se avalia em cada dimensão e por quais públicos são respondidas as questões.

\section{QUADRO 1}

\section{MATRIZ COM AS DIMENSÕES DO CLIMA ESCOLAR E PÚBLICO-ALVO}

\begin{tabular}{|c|c|c|}
\hline \multicolumn{3}{|c|}{ CLIMA ESCOLAR - MATRIZ } \\
\hline DIMENSÃO & CONCEITO & GRUPO \\
\hline $\begin{array}{l}\text { 1. As relações com } \\
\text { o ensino e com a } \\
\text { aprendizagem }\end{array}$ & $\begin{array}{l}\text { A boa qualidade dessa dimensão se assenta na percepção } \\
\text { da escola como um lugar de trabalho efetivo com o } \\
\text { conhecimento, que investe no êxito, motivação, participação } \\
\text { e bem-estar dos alunos, promove o valor da escolarização } \\
\text { e o sentido dado às aprendizagens. Supõe também a } \\
\text { atuação eficaz de um corpo docente estável e a presença de } \\
\text { estratégias diferenciadas, que favoreçam a aprendizagem } \\
\text { de todos, e o acompanhamento contínuo, de maneira a que } \\
\text { nenhum aluno fique para trás. }\end{array}$ & $\begin{array}{l}\text { Aluno } \\
\text { Professor } \\
\text { Gestor }\end{array}$ \\
\hline $\begin{array}{l}\text { 2. As relações sociais e } \\
\text { os conflitos na escola }\end{array}$ & $\begin{array}{l}\text { Refere-se às relações, aos conflitos e à percepção sobre } \\
\text { a qualidade do tratamento entre os membros da escola. } \\
\text { Abrange também a identificação pelos adultos das situações } \\
\text { de intimidação e maus tratos vivenciadas nas relações entre } \\
\text { pares, e a corresponsabilidade dos profissionais da escola } \\
\text { nos problemas de convivência. A boa qualidade do clima } \\
\text { relacional é resultante das relações positivas que ocorrem } \\
\text { nesse espaço, das oportunidades de participação efetiva, } \\
\text { da garantia do bem-estar, respeito e apoio entre as pessoas, } \\
\text { promovendo continuamente o sentimento de pertencimento. }\end{array}$ & $\begin{array}{l}\text { Aluno } \\
\text { Professor } \\
\text { Gestor }\end{array}$ \\
\hline $\begin{array}{l}\text { 3. As regras, as sanções } \\
\text { e a segurança na escola }\end{array}$ & $\begin{array}{l}\text { Essa dimensão diz respeito às percepções dos gestores, } \\
\text { professores e alunos em relação às intervenções nos } \\
\text { conflitos interpessoais na escola. Abrange a elaboração, } \\
\text { conteúdo, legitimidade e equidade na aplicação das regras } \\
\text { e sanções, identificando os tipos de punições geralmente } \\
\text { empregados. Compreende, ainda, a ordem, justiça, } \\
\text { tranquilidade, coerência e segurança no ambiente escolar. }\end{array}$ & $\begin{array}{l}\text { Aluno } \\
\text { Professor } \\
\text { Gestor }\end{array}$ \\
\hline $\begin{array}{l}\text { 4. As situações de } \\
\text { intimidação entre } \\
\text { alunos }\end{array}$ & $\begin{array}{l}\text { Essa dimensão trata da identificação das situações de } \\
\text { intimidação e maus tratos vivenciadas nas relações entre } \\
\text { pares e de bullying percebidos pelos alunos e dos locais em } \\
\text { que ocorrem. }\end{array}$ & Aluno \\
\hline
\end{tabular}




\begin{tabular}{|c|c|c|}
\hline DIMENSÃO & CONCEITO & GRUPO \\
\hline $\begin{array}{l}\text { 5. A família, a escola e a } \\
\text { comunidade }\end{array}$ & $\begin{array}{l}\text { Refere-se à percepção da qualidade das relações entre } \\
\text { escola, família e comunidade, compreendendo o respeito, } \\
\text { a confiança e o apoio entre esses grupos. Envolve o } \\
\text { sentimento de ser parte integrante de um grupo que } \\
\text { compartilha objetivos comuns. }\end{array}$ & $\begin{array}{l}\text { Aluno } \\
\text { Professor } \\
\text { Gestor }\end{array}$ \\
\hline $\begin{array}{l}\text { 6. A infraestrutura e a } \\
\text { rede física da escola }\end{array}$ & $\begin{array}{l}\text { Trata-se da percepção da qualidade da infraestrutura e do } \\
\text { espaço físico da escola, do seu uso, adequação e cuidado. } \\
\text { Refere-se a como os equipamentos, mobiliários, livros e } \\
\text { materiais estão preparados e organizados, para favorecer a } \\
\text { acolhida, o livre acesso, a segurança, o convívio e o } \\
\text { bem-estar, nesses espaços. }\end{array}$ & $\begin{array}{l}\text { Aluno } \\
\text { Professor } \\
\text { Gestor }\end{array}$ \\
\hline $\begin{array}{l}\text { 7. As relações com o } \\
\text { trabalho }\end{array}$ & $\begin{array}{l}\text { Trata-se dos sentimentos dos gestores e professores com } \\
\text { seu ambiente de trabalho e as instituições de ensino. } \\
\text { Abrange as percepções quanto à formação e qualificação } \\
\text { profissional, às práticas de estudos e às reflexões sobre as } \\
\text { ações, à valorização, satisfação e motivação para a função } \\
\text { que desempenham e ao apoio que recebem dos gestores e } \\
\text { demais profissionais. }\end{array}$ & $\begin{array}{l}\text { Professor } \\
\text { Gestor }\end{array}$ \\
\hline $\begin{array}{l}\text { 8. A gestão e a } \\
\text { participação }\end{array}$ & $\begin{array}{l}\text { Abrange a percepção quanto à qualidade dos processos } \\
\text { empregados para identificação das necessidades da escola, } \\
\text { intervenção e avaliação dos resultados. Inclui também a } \\
\text { organização e a articulação entre os diversos setores e } \\
\text { atores que integram a comunidade escolar, no sentido de } \\
\text { promover espaços de participação e cooperação, na busca } \\
\text { de objetivos comuns. }\end{array}$ & $\begin{array}{l}\text { Professor } \\
\text { Gestor }\end{array}$ \\
\hline
\end{tabular}

Fonte: Vinha, Morais e Moro (2017).

Tais instrumentos foram construídos pela equipe da pesquisa já mencionada, e sua aplicação foi realizada na versão impressa e por meio eletrônico (on-line e off-line), entre outubro e dezembro de 2015. A construção se deu a partir de uma ampla revisão de literatura e de questionários nacionais e internacionais. Optou-se por um modelo que se caracterizasse por uma linguagem clara e objetiva, de forma que as alternativas de respostas aos itens se adequassem ao formato de uma escala Likert, de modo que cada item apresenta quatro possibilidades de resposta, correspondendo a uma escala de um a quatro pontos, variando de uma menor concordância para uma maior concordância. Salienta-se que, após as testagens empíricas, com uma amostra total de mais de 10.000 participantes, entre alunos, professores e gestores do $7^{\circ}$ ano do ensino fundamental II ao $3^{\circ}$ ano do ensino médio, de mais de 70 escolas brasileiras públicas e particulares, os questionários passaram por reestruturações, no sentido de se tornarem mais enxutos, acurados e aptos a atender aos critérios de confiabilidade e de validade de construto. Em suas versões finais, as quais foram validadas pelos procedimentos estatísticos de análise de componentes principais - em que a maioria dos itens apresentou carga componencial acima de 0,30 nas diferentes dimensões dos instrumentos - e de confiabilidade composta, com coeficientes entre 0,80 e 0,90, os questionários chegaram às seguintes estruturas, no que se refere ao número de itens, conforme as diferentes dimensões de avaliação do clima escolar: 104 itens para alunos, 123 para professores e 130 para gestores (VINHA; MORAIS; MORO, 2017).

Em sua construção, garantiu-se que os três questionários, destinados a cada um dos públicos, contivessem uma inter-relação de forma coesa, contemplando 
as percepções e expectativas de alunos, professores e gestores sobre temas comuns e também sobre temas particulares de cada público, conforme é revelado no Quadro 2.

\section{QUADRO 2}

NATUREZA DOS ITENS EM CADA UM DOS INSTRUMENTOS DE CLIMA ESCOLAR

\begin{tabular}{|l|c|c|c|}
\hline NATUREZA & ALUNOS & PROFESSORES & GESTORES \\
\hline Itens de relação & 69 & 94 & 85 \\
\hline Itens exclusivos & 35 & 29 & 45 \\
\hline Total & 104 & 123 & 130 \\
\hline
\end{tabular}

Fonte: Elaboração própria, com base nos dados da pesquisa (VINHA; MORAIS; MORO, 2017).

Nos questionários, portanto, foram elaborados itens exclusivos, referentes à especificidade de cada ator, assim como itens de relação, os quais se referem exclusivamente a cada um dos três públicos investigados. Os itens de relação permitem verificar a percepção de cada um dos três membros da comunidade escolar acerca de um mesmo fenômeno, possibilitando comparar as informações para fornecer um retrato do clima escolar da instituição.

Para avaliar o clima escolar, nas diferentes dimensões contempladas pelos instrumentos, calcula-se, primeiramente, a pontuação média obtida em cada dimensão, por meio da média aritmética dos valores obtidos no conjunto dos itens da respectiva dimensão. Além disso, pode-se avaliar uma dimensão do clima de forma geral como mais positiva, intermediária ou negativa, em que, com base no cálculo da pontuação média obtida em cada dimensão, propõe-se a organização e codificação dos escores numéricos em três níveis. Para isso, divide-se o intervalo de valores possíveis para as médias de 1 a 4 em três subintervalos iguais. O primeiro tercil conterá as médias com valores de 1 a 2,25: nível negativo; o segundo tercil, de 2,26 a 2,75: nível intermediário; e o terceiro tercil, de 2,76 até 4,00: nível positivo. $^{4}$

\section{Desempenho acadêmico}

Já com relação ao instrumento destinado à avaliação de desempenho acadêmico, optamos pela escolha de uma avaliação externa oficial, cujos resultados fossem disponibilizados ao público. O Enem é o principal e único índice de avaliação externa, do ensino médio do país, com aplicação anual e, ao menos até o momento da coleta da pesquisa, tinha divulgação do resultado por escola, ${ }^{5}$ diferentemente de outros indicadores, cujos resultados são amostrais. Além

4 Essa forma de mensuração foi adotada pela equipe de pesquisadores que realizaram a construção e validação dos instrumentos, para que seja possível extrair "as frequências de avaliação positiva, intermediária e negativa de cada uma das dimensões do clima, de modo a conseguir os diagnósticos referentes às percepções dos atores escolares sobre sua instituição de ensino" (VINHA; MORAIS; MORO, 2017, p. 74). Tal procedimento tem também como propósito comunicar os resultados de avaliação do clima de maneira que possam ser interpretados mais facilmente pela comunidade escolar, quando comparado por resultados apresentados por meio de médias.

5 Observa-se que no início de 2017 foi anunciado o encerramento da divulgação anual das médias por escola, conforme nota divulgada: http://portal.inep.gov.br/artigo/-/asset_publisher/B4AQV9zFY7BV/ content/nota-de-esclarecimento-encerramento-do-enem-por-escola/21206. Acesso em: jan. 2018. 
disso, esse exame é o principal processo seletivo para ingresso nas universidades brasileiras e sua utilização vem crescendo também nas instituições federais de ensino superior (Ifes) de Portugal (INSTITUTO NACIONAL DE ESTUDOS E PESQUISAS EDUCACIONAIS ANÍSIO TEIXEIRA - INEP, 2016).

Nesta pesquisa, empregaram-se os dados apenas de escolas que se enquadravam nos critérios de divulgação, a saber: adesão de no mínimo dez alunos matriculados no ensino médio da instituição; e percentual de participação atingido por, no mínimo, 50\% dos alunos matriculados (INEP, 2016).

O exame é dividido por áreas de conhecimento: ciências da natureza e suas tecnologias; ciências humanas e suas tecnologias; linguagens, códigos e suas tecnologias; matemática e suas tecnologias; e redação. As quatro primeiras são de natureza objetiva e a última é dissertativa. Em cada área consideram-se a nota mínima de zero e a máxima de 1.000. Neste trabalho, optamos por mensurar o desempenho de forma única e, assim, calculamos a média aritmética simples, contando com cada uma das áreas que correspondiam às provas objetivas. Em nossas análises consideramos também a nota da redação, porém de modo separado das demais áreas.

Além disso, incluíram-se, com base nos objetivos deste estudo, os seguintes dados contextuais, disponibilizados juntamente com a nota do Enem, que permitem conhecer melhor as especificidades de cada unidade escolar: taxa de participação, que consiste no valor percentual de alunos concluintes do ensino médio que realizaram a prova do Enem; e o indicador de nível socioeconômico (Inse) (INEP, 2014).

O Inse é um indicador gerado por escola e consiste em uma medida que procura situar o conjunto de alunos atendidos por cada escola em um estrato, considerando o nível de escolaridade dos pais, a posse de bens domésticos, renda e contratação de serviços pelas famílias dos alunos. A medida de nível socioeconômico dos alunos, de cada escola, em 2015, foi calculada utilizando-se os dados da Avaliação Nacional do Rendimento Escolar (Anresc, também denominada Prova Brasil) e da Avaliação Nacional da Educação Básica (Aneb) de 2011 e 2013, assim como os dados do Enem 2011 e 2013 (INEP, 2014). A metodologia utilizada no cálculo da medida de nível socioeconômico dos alunos tem por característica o uso de sete níveis ordinais, aplicando-se a Teoria de Resposta ao Item, um modelo matemático probabilístico. O nível socioeconômico da escola, por sua vez, é extraído a partir da média aritmética simples da medida de nível socioeconômico de seus respectivos alunos, sendo criados, a partir da análise de cluster, sete grupos organizados da seguinte maneira: muito baixo, baixo, médio baixo, médio, médio alto, alto e muito alto. O Inep afirma que o Inse é um indicador consistente para a contextualização do desempenho das escolas (INEP, 2014).

Ressalta-se que o Enem é uma avaliação voltada para alunos concluintes da educação básica, ou seja, alunos do $3^{\circ}$ ano do ensino médio, todavia, seus objetivos se fundamentam na avaliação de toda trajetória educacional dessa fase educacional, portanto, considera-se que avalia a escola como um todo, não se restringindo ao desempenho dos anos finais. 


\section{A ANÁLISE CONSIDERANDO OS DADOS CONTEXTUAIS}

Os dados contextuais são identificados e avaliados pelo cálculo do efeito escola, cujo surgimento é explicitado por Brault (2004), em função de uma conjuntura histórica. Esse pesquisador dedicou-se aos estudos das variáveis clima e desempenho, examinando-as sob o efeito escola. Ele explica que, após a política internacional de democratização escolar, observava-se que escolas se diferenciavam muito entre si no quesito desempenho acadêmico. Primeiramente, foram notadas distinções em função da natureza escola, se era pública ou privada; depois, em relação à clientela que frequentava, com condição socioeconômica desfavorecida e dificuldades de aprendizagem; ou pelo programa adotado na instituição. Contudo, percebia-se que havia algo além desses fatores que poderia ser levado em conta, pois existiam escolas que, apesar dos problemas, se destacavam mesmo diante dessas dificuldades. Verificou-se que tais escolas obtinham um controle maior dessas situações adversas, guiando-se principalmente com planejamento e sensibilidade. Assim, o efeito escola se caracteriza pela capacidade da escola em ajudar os alunos a atingir um desempenho acima do esperado, a despeito das condições contextuais em que está imersa.

Segundo Travitzki (2013), o efeito escola é analisado estatisticamente, controlando-se uma ou mais variáveis contextuais (como, por exemplo, o nível socioeconômico), sendo possível prever o desempenho. Trata-se de um cálculo que tem em vista a nota residual de cada escola, calculando-se a diferença entre seu desempenho real e o desempenho esperado, mediante modelo de regressão. Esse modelo tem por objetivo considerar o trabalho feito pela escola.

Tal ação se justifica, pois algumas escolas inserem-se em contextos favoráveis que beneficiam o aluno, viabilizando um melhor desempenho no Enem; assim, examinar apenas as notas brutas do Enem, como são divulgadas, não avalia de fato o trabalho da escola, porque, na realidade, ocorre o oposto: avalia-se um efeito do aluno sobre a escola e não um efeito da escola sobre o aluno. O pesquisador afirma que foi possível constatar que apenas $7 \%$ do desempenho do aluno é explicado pela escola que frequenta, sendo o restante influenciado por elementos contextuais (TRAVITZKI, 2013).

Sob tais considerações e mediante a realidade brasileira, caracterizada por expressivos contrastes socioeconômicos, optou-se por relacionar o clima escolar com desempenho acadêmico por meio de dados contextuais, possibilitando uma análise melhor da escola e evitando que fatores extraescolares interferissem na avaliação do impacto do clima escolar sobre o desempenho.

\section{FORMA DE ANÁLISE DOS RESULTADOS}

Contou-se com os programas estatísticos IBM@ SPSS@ Statistics Version 19.0 e PSPP@ Statistics Analysis Of Sampled Data, para desenvolver as análises.

Utilizaram-se os testes inferenciais (qui-quadrado e regressão linear), a fim de verificar as associações e relações entre variáveis: o clima escolar, em cada uma das dimensões avaliadas; e o desempenho no Enem 2015, além dos dados contextuais. A distribuição de normalidade foi avaliada pelo teste de Shapiro-Wilk com 
correção de Lillifors. Já as variáveis quantitativas foram descritas pela média e intervalo de confiança de 95\% (IC95\%), enquanto as variáveis qualitativas foram descritas pela distribuição de frequências relativa (\%) e absoluta (f). Para analisar a influência do clima e dados contextuais (variável independente) sobre o desempenho escolar (variável dependente), foi realizada a regressão linear múltipla pelo método Enter, sendo que o $\mathrm{R}^{2}$ foi analisado para observar o coeficiente de determinação de variância explicada pelo modelo (DAWSON; TRAPP, 2001).

Já para o cálculo do efeito escola sobre o desempenho no Enem 2015 das 46 escolas, levou-se em conta a variável Inse, de modo que, a partir do modelo de regressão linear, se extraiu o valor residual de cada escola, o qual foi determinado pela diferença entre o valor previsto pela equação de regressão e o valor observado. Por fim, para analisar os dados do clima escolar, de acordo com o desempenho das escolas, foi efetuada a divisão das escolas em quartis, com base na dispersão e tendências, conforme os dados residuais.

\section{RESULTADOS E DISCUSSÕES}

Apresentaremos os resultados da regressão linear múltipla, após os quais se adotou o cálculo do efeito escola, controlando os dados contextuais.

\section{REGRESSÃO LINEAR MÚLTIPLA}

A Tabela 1 traz os resultados encontrados. Nota-se, no modelo 1, a influência significativa na previsão do desempenho, com base na média do Enem 2015, das variáveis independentes Inse e taxa de participação, ambas apresentando coeficiente B (slope) positivo, demonstrando que, quanto maior o Inse e a taxa de participação da escola, mais alta foi a média prevista de desempenho no Enem 2015. Esse primeiro modelo mostra-se capaz para explicar $43,2 \%\left(\mathrm{R}^{2}\right)$ da variação dos escores da pontuação da média do Enem 2015. Ademais, é possível perceber que a variação dos intervalos de confiança estima uma redução de $2,7 \%$ na capacidade de explicar os resultados ( $\mathrm{R}^{2}$ ajustado $\left.=0,405=40,5 \%\right)$. 
TABELA 1

COEFICIENTES DO INSE E TAXA DE PARTICIPAÇÃO, NO MODELO 1, E DO CLIMA ESCOLAR NA DIMENSÃO INTIMIDAÇÃO E INSE, NO MODELO 2, TENDO COMO VARIÁVEL DEPENDENTE A MÉDIA DE DESEMPENHO NO ENEM 2015

\begin{tabular}{|c|c|c|c|c|c|c|c|c|c|}
\hline \multirow[b]{2}{*}{ MODELOS } & & \multicolumn{2}{|c|}{ COEFICIENTES } & \multirow[b]{2}{*}{$\mathrm{T}$} & \multirow[b]{2}{*}{$\mathbf{P}$} & \multicolumn{2}{|c|}{ IC $95 \%$} & \multirow[b]{2}{*}{$\mathbf{R}^{2}$} & \multirow{2}{*}{$\begin{array}{c}\mathbf{R}^{2} \\
\text { AJUSTADO }\end{array}$} \\
\hline & & B & $\begin{array}{c}\text { ERRO } \\
\text { PADRÃO }\end{array}$ & & & INF & SUP & & \\
\hline \multirow[t]{3}{*}{ Modelo 1} & (Constante) & 382,80 & 21,62 & 17,71 & 0,000 & 339,20 & 426,40 & \multirow{3}{*}{0,432} & \multirow{3}{*}{0,405} \\
\hline & Inse & 13,69 & 3,76 & 3,64 & $0,001^{*}$ & 6,10 & 21,28 & & \\
\hline & $\begin{array}{c}\text { Taxa de } \\
\text { participação }\end{array}$ & 0,89 & 0,26 & 3,47 & $0,001^{*}$ & 0,38 & 1,42 & & \\
\hline \multirow[t]{3}{*}{ Modelo 2} & (Constante) & 301,42 & 61,53 & 4,89 & 0,000 & 177,32 & 425,52 & \multirow{3}{*}{0,364} & \multirow{3}{*}{0,334} \\
\hline & Intimidação & 44,65 & 17,99 & 2,48 & $0,017^{*}$ & 8,37 & 80,94 & & \\
\hline & Inse & 16,73 & 3,87 & 4,31 & $0,0001^{*}$ & 8,91 & 24,55 & & \\
\hline
\end{tabular}

Fonte: Elaboração própria com base nos dados do Enem 2015 e de clima escolar (2017).

Ainda na Tabela 1, observa-se que o modelo 2 também se revelou significativo, explicando $36,4 \%\left(\mathrm{R}^{2}\right)$ da variação dos escores de pontuação média do Enem 2015. Nesse caso, estima-se uma redução de $3 \%$ na capacidade de explicar os resultados da população ( $\mathrm{R}^{2}$ ajustado $=0,334=33,4 \%$ ), em que se identifica influência significante, ao prever o desempenho perante as variáveis do clima escolar, na dimensão Intimidação (percepção de alunos) e Inse, evidenciando que ambas apresentaram coeficiente B (slope) positivo e confirmando que, quanto melhor o clima escolar, apenas na dimensão Intimidação, juntamente com o Inse, maior foi a média prevista no Enem.

A taxa de participação demonstra, de modo geral, quantos alunos regularmente matriculados veem possibilidades em dar prosseguimento a seus estudos, no ensino superior. Com base no Modelo 1 de regressão linear, podemos indicar que as escolas com uma taxa maior de participação no Enem possuem uma nota média da escola também maior. Entendemos esse fenômeno como se algumas escolas tivessem uma atmosfera mais propícia, ou talvez um clima escolar mais positivo, para que alunos desejassem e realizassem esse exame e, como consequência, quanto melhor é essa atmosfera, maior seria a participação desses alunos, os quais tenderiam igualmente a alcançar melhor desempenho no Enem.

Também se observa, no Modelo 2, que a única dimensão do clima escolar que se apresentou como preditora do desempenho foi a Intimidação entre pares, dimensão incluída apenas nos questionários dos alunos, indicando que, em escolas em que há menos situações de vulnerabilidade, com um ambiente mais seguro e que garante um bem-estar maior, tem-se como consequência um desempenho melhor.

Segundo Díaz-Aguado (2015), nas situações de intimidação entre pares, também conhecidas como bullying, as consequências são para todos os envolvidos e até mesmo para a sociedade. Ao alvo do bullying, causam-se medo e rejeição, perda de 
confiança em si mesmo e nos outros, diminuindo ainda o rendimento acadêmico e a autoestima. Para os autores do bullying, diminuem a capacidade de empatia, sensibilidade e solidariedade e há propensão de se tornarem violentos quando adultos. Existe também consequência para o ambiente escolar, reduzindo a qualidade de vida das pessoas e dificultando a difusão de valores positivos na escola.

Ambas as variáveis - Taxa de Participação e clima na dimensão Intimidação - foram previsoras do desempenho, acompanhadas do Indicador de Nível Socioeconômico (Inse).

Diante do fato de não ter sido encontrada relação estatisticamente significante entre desempenho e o clima escolar geral e as demais dimensões, optou-se por utilizar na pesquisa um tipo de análise que controla a variável contextual (condição socioeconômica dos alunos da escola), ao relacionar o clima com o desempenho, de modo a verificar se o clima escolar positivo poderia causar benefícios ao desempenho, o que se relata no item seguinte.

\section{EFEITO ESCOLA}

Como já explicitado, o efeito escola foi calculado a partir do valor residual da nota do Enem de cada escola, extraído da diferença entre o valor esperado e o valor obtido, quando se considera o Inse, o que, por sua vez, corresponde aos índices socioeconômicos da escola e de seus respectivos alunos, incluindo informação acerca do nível de escolaridade dos pais, posse de bens domésticos, renda e contratação de serviço pelas famílias. Desse modo, ilustra-se, no Gráfico 1, a linha de regressão linear de desempenho no Enem 2015 das 46 escolas da amostra da pesquisa, de acordo com o Inse. É importante esclarecer que cada escola participante é representada no gráfico por um círculo colorido. 


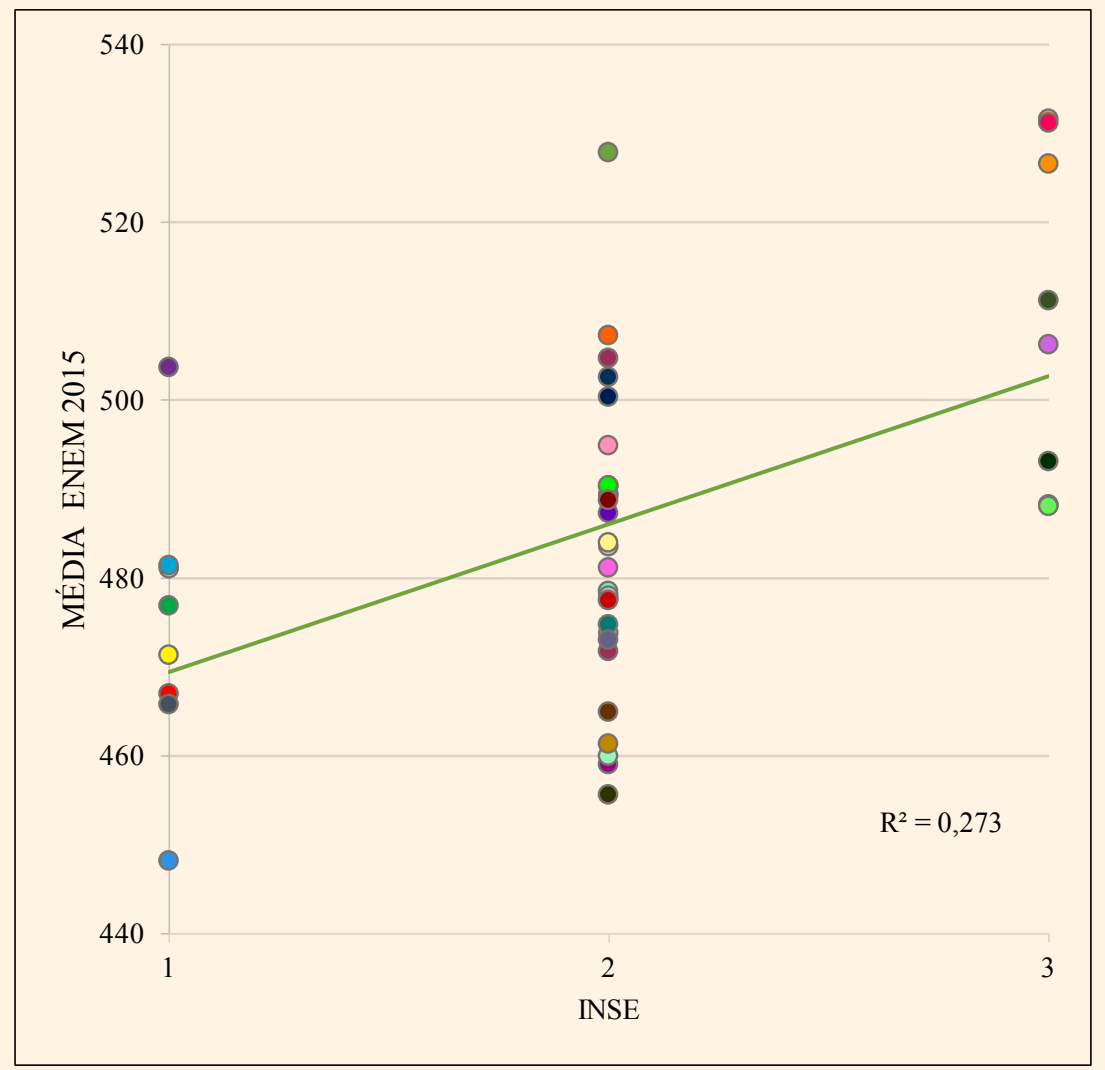

Nota: Inse 1 indica nível médio baixo; Inse 2, nível médio; e Inse 3, nível médio alto.

Fonte: Elaboração dos autores com base nos dados do Enem 2015 (2017).

Nota-se que, à medida que o Inse classificado como de tipo 1 (nível socioeconômico médio baixo), 2 (nível médio) ou 3 (nível médio alto) aumenta, inclina-se mais a linha de previsão, indicando maior nota no Enem. Verifica-se que, em relação às escolas, representadas pelos círculos, algumas se situam muito acima, outras muito abaixo e há aquelas próximas da linha de regressão, o que retrata os desempenhos muito acima, muito abaixo ou próximos ao esperado obtidos por elas.

Assim, este trabalho se desdobra na intenção de verificar se o clima escolar desempenharia o papel de fator protetivo para o desempenho no Enem, com especial atenção às escolas com contextos socioeconômicos desfavoráveis, e se haveria dimensões do clima ou de públicos que exerceriam uma maior influência sobre o desempenho, em função do nível socioeconômico da escola.

A distância apresentada entre a média de cada escola e a linha de regressão revela os dados residuais, ou seja, valores positivos ou negativos de desempenho obtido pela escola, segundo o que seria esperado, dado seu contexto socioeconômico. Na Tabela 2, foi efetuada a divisão das escolas em quartis, com 
base na dispersão e tendências, conforme os dados residuais. De acordo com esses valores, as escolas foram classificadas em três grupos:

- o Grupo 1, com valores entre os $25 \%$ inferiores, com valor residual entre -30,48 e -12,47, agrega as escolas com desempenho bem abaixo do esperado;

- o Grupo 2, com valores entre os $25 \%$ inferiores e $25 \%$ superiores, com valor residual entre -12 e 9,51, engloba escolas com desempenho próximo ao esperado;

- o Grupo 3, com valores entre os $25 \%$ superiores, com valor residual de 10 a 41,73, inclui escolas que tiveram desempenho bem acima do esperado.

Assim, tem-se 12 escolas no Grupo 1, 23 no Grupo 2 e 11 no Grupo 3.

TABELA 2

VARIÂNCIA DOS DADOS RESIDUAIS DA ANÁLISE DO DESEMPENHO ACIMA OU ABAIXO DO ESPERADO NO ENEM 2015

\begin{tabular}{|c|c|c|c|}
\hline & & $\begin{array}{c}\text { RESÍDUO } \\
\text { NÃO PADRONIZADO }\end{array}$ & RESÍDUO PADRONIZADO \\
\hline N - Válidos & & 46 & 46 \\
\hline $\mathrm{N}$ - Ausentes & & 0 & 0 \\
\hline Variância & & 278,957 & 0,978 \\
\hline Mínimo & & $-30,48585$ & $-1,80489$ \\
\hline Máximo & & 41,72915 & 2,47054 \\
\hline \multirow{3}{*}{ Percentual } & 25 & $-12,474605$ & $-0,738548$ \\
\hline & 50 & $-0,4896047$ & $-0,028987$ \\
\hline & 75 & 9,5124416 & 0,5631755 \\
\hline
\end{tabular}

Fonte: Elaboração dos autores com base nos dados do Enem 2015 (2017).

Com a intenção de analisar as escolas com desempenhos muito abaixo do esperado e muito acima do esperado, optou-se por realizar uma análise mais pontual nas escolas dos grupos 1 e 3 , examinando seus respectivos climas. A finalidade pautou-se em buscar compreender se o clima escolar, além de proporcionar bem-estar aos que convivem no espaço institucional educativo, poderia ter reflexos no desempenho acadêmico, nesse caso, sendo mediado por dados contextuais.

De maneira distinta das análises anteriores, que se basearam nos dados por escolas, nessa etapa, os dados foram extraídos da amostra de indivíduos, sendo os sujeitos em questão: alunos, professores e gestores das 46 escolas. Na Tabela 3, observamos que a amostra conta com 1.364 alunos das escolas dos grupos 1 e 3 , sendo 52,6\% no Grupo 1 e 47,4\% no Grupo 3; já os professores totalizam 215 (50,2\% no Grupo 1 e 49,8\% no Grupo 3), enquanto os gestores somam 87, 51,7\% e $48,3 \%$, respectivamente, nos dois grupos. 
ALUNOS, PROFESSORES E GESTORES DAS ESCOLAS DOS GRUPOS 1 E 3

\begin{tabular}{l|c|c|c}
\hline \multirow{3}{*}{ Glunos } & 1 & FREQUÊNCIA & PERCENTAGEM \\
\cline { 2 - 4 } & 3 & 717 & 52,6 \\
\cline { 2 - 4 } & Total & 647 & 47,4 \\
\hline \multirow{4}{*}{ Professores } & 1 & 1364 & 100 \\
\cline { 2 - 4 } & 3 & 108 & 50,2 \\
\cline { 2 - 4 } & Total & 107 & 49,8 \\
\hline \multirow{3}{*}{ Gestores } & 1 & 215 & 100 \\
\cline { 2 - 4 } & 3 & 45 & 51,7 \\
\cline { 2 - 4 } & Total & 42 & 48,3 \\
\hline
\end{tabular}

Fonte: Elaboração dos autores com base nos dados do Enem 2015 (2017).

Como mencionado anteriormente, os questionários utilizados na avaliação de clima escolar foram construídos de forma que seus itens têm quatro opções de respostas, correspondendo a uma escala de um a quatro pontos, da menor concordância à maior concordância. Assim, na análise do clima geral e por dimensões, na perspectiva de cada público investigado, considerou-se o cálculo da média do conjunto de itens. Para uma análise mais ilustrativa, transformaram-se os valores das médias em níveis de acordo com os tercis: até 2,25 pontos avaliação negativa; de 2,26 a 2,75 pontos avaliação intermediária; e de 2,76 a 4 pontos avaliação positiva. Neste artigo, optou-se por apresentar os dados resultantes da avaliação positiva do clima escolar.

O Gráfico 2 revela que alunos, professores e gestores das escolas do Grupo 3 obtiveram uma avaliação mais positiva do clima escolar geral do que os das escolas do Grupo 1. Nota-se ainda que foi na avaliação dos alunos que se indicou uma discrepância mais acentuada em relação à avaliação positiva do clima, pois, enquanto as escolas do Grupo 1 obtiveram percentual de 32\%, aquelas do Grupo 3 atingiram $47 \%$, totalizando uma diferença de 15 pontos percentuais; em contrapartida, a diferença de professores marcou $4 \%$ e a de gestores, $13 \%$. 


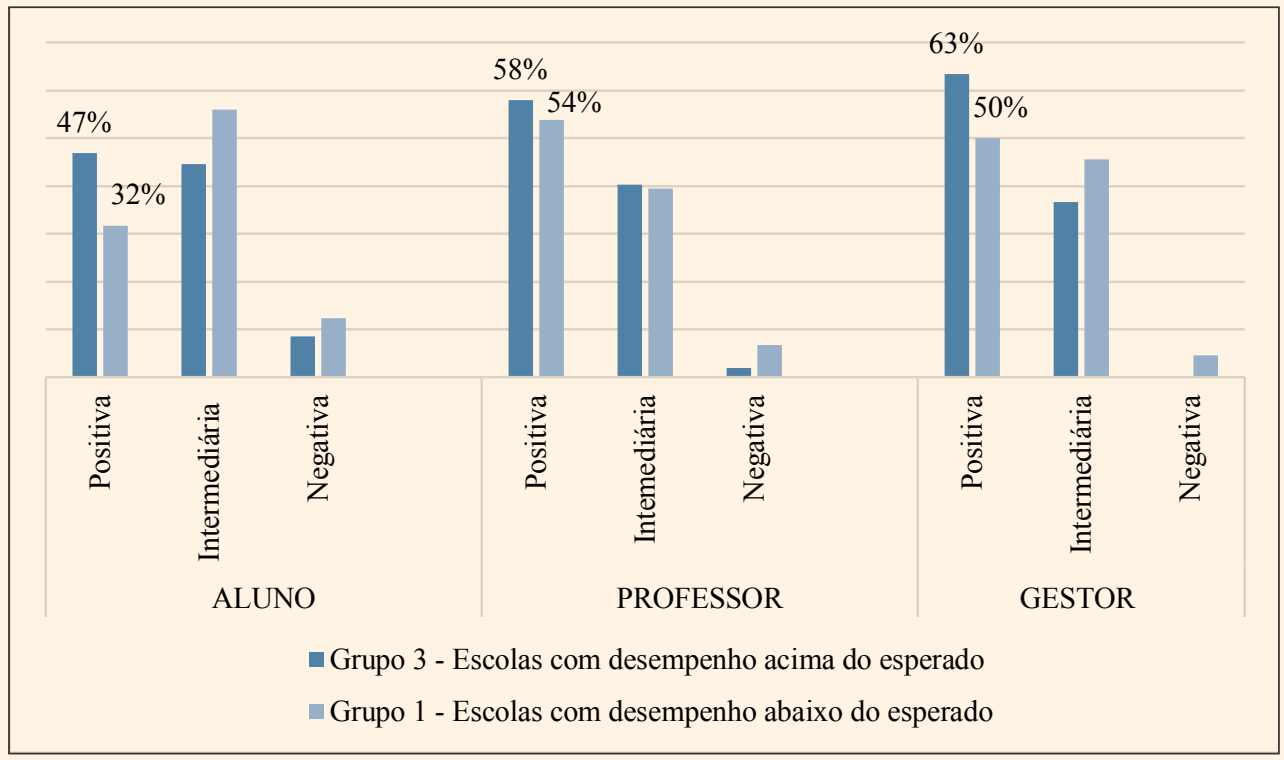

Fonte: Elaboração dos autores com base nos dados do Enem 2015 e de clima escolar (2017).

Salienta-se que, em uma avaliação de clima escolar, é natural algumas situações convergirem sob uma mesma resposta ou tendência, nos diferentes públicos escolares pesquisados. Também as ocorrências de divergências acontecem, pois trata-se de diferentes perspectivas. Cada público analisa o clima escolar sob seu ponto de vista, diante de suas expectativas e anseios. Isso reforça a importância da avaliação de clima escolar, destacada na introdução deste artigo, pois confirmamos que se revelam percepções antes não bem clarificadas nas instituições.

Além disso, podemos aferir que a situação do clima nas escolas, mais explicitamente a partir da percepção dos alunos, teve como consequência um desempenho bem acima ou bem abaixo do esperado no Enem. Claro (2013), dentro de seu entendimento de clima escolar, explica que os alunos devem ocupar um lugar central na escola, não por considerá-los mais importantes dentre os atores que compõem a comunidade escolar, mas por serem os protagonistas em orientar os processos educativos - que é objetivo primordial de uma escola. Assim, os resultados apresentados no Gráfico 2 indicam que alunos, especialmente das escolas do Grupo 1, apontam fragilidades nas relações estabelecidas em suas escolas e, do mesmo modo, nos espaços que as compõem.

Destaca-se ainda no mesmo gráfico a avaliação dos discentes, a qual se mostrou com um percentual positivo menor, tanto nas escolas do Grupo 1 como nas do Grupo 3, ao se comparar com as avaliações de professores e gestores, revelando que os alunos se posicionam de forma mais crítica do que os professores e gestores.

Considerando que foi na perspectiva dos alunos que observamos uma maior discrepância do clima escolar positivo, perante as escolas com desempenho acima e abaixo do esperado e, ainda, em razão de a avaliação positiva desse 
público das escolas do Grupo 1 ter sido mais baixa, quando comparada à de professores e gestores, optamos por apresentar mais detalhadamente os resultados dos discentes, especificamente. Buscamos analisar o porquê dessa discrepância, verificando se haveria dimensões do clima que exerceram uma maior influência sobre o desempenho e em quais itens seria possível notar uma diferença significativa, na percepção dos alunos, entre as escolas do Grupo 1 ou 3. O intuito pauta-se na busca de compreender a natureza dessas relações, por meio de uma análise qualitativa, procurando nos referenciar sobre como a literatura disserta sobre as questões que mais foram significativas.

No Gráfico 3, em que explicitamos a avaliação positiva dos alunos em cada uma das dimensões do clima escolar, observa-se que, nas escolas com desempenho acima do esperado, o clima em cada uma das dimensões evidenciou uma tendência mais positiva do que em escolas com desempenho abaixo do esperado, com exceção da dimensão Família. Em todos esses casos, as associações entre as variáveis foram estatisticamente significantes (para $\mathrm{p}=0,05$; teste qui-quadrado), entre os grupos 1 e 3 . Vê-se, por conseguinte, que as avaliações foram mais negativas nas escolas do Grupo 1 e mais positivas naquelas do Grupo 3.

Além disso, é possível perceber que as dimensões com maior discrepância entre as escolas dos grupos 1 e 3 são Aprendizagem (diferença de 19\%) e Regras (diferença de 13\%). Esse resultado está em consonância com o levantamento de outros resultados de pesquisas, como mencionado neste texto, anteriormente (MA; KLINGER, 2000; SUMMER, 2006; TAYLOR, 2008; CANDIAN; RESENDE, 2013; CANGUÇU, 2015). Tais dados denotam o quão importantes são as questões relacionais em função de um melhor desempenho, tendo em vista as situações contextuais.

\section{GRÁFICO 3}

AVALIAÇÃO POSITIVA DOS ALUNOS DAS ESCOLAS DOS GRUPOS 1 E 3, SEGUNDO A DIMENSÃO

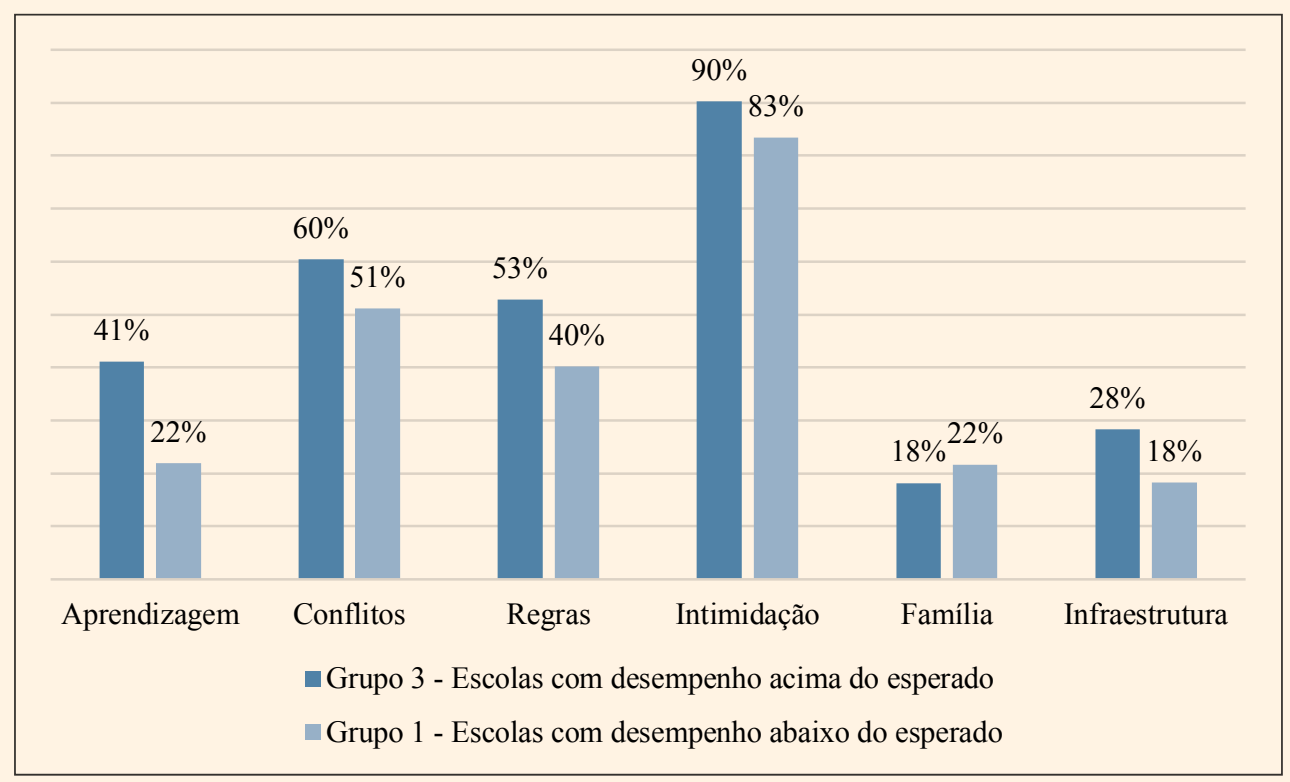

Fonte: Elaboração dos autores com base nos dados do Enem 2015 e de clima escolar (2017). 
Observamos, ainda, diferenças significativas entre os grupos 1 e 3, nas dimensões Infraestrutura, Conflitos e Intimidação, não ocorrendo o mesmo com a dimensão Família, dado que se pode esperar, em face da idade dos alunos de ensino médio. Entendemos que, nesses casos, a família geralmente confia mais nas responsabilidades desses alunos e em escolas com um clima melhor, o que pode acontecer diferentemente nas escolas com clima mais negativo, nas quais os pais, muitas vezes, são chamados à escola por questões disciplinares ou de problemas com a aprendizagem.

Voltemos a atenção às dimensões que mais apresentaram discrepâncias, na avaliação de escolas dos grupos 1 e 3: Aprendizagem e Regras. Dessa forma, nos dedicaremos a verificar o que a literatura menciona a respeito desses dois temas e procuraremos entendê-los, buscando respostas como essas escolas lidam com tais dimensões.

A Dimensão 1, denominada As relações com o ensino e com a aprendizagem, tem a seguinte caracterização:

\begin{abstract}
A boa qualidade dessa dimensão se assenta na percepção da escola como um lugar de trabalho efetivo com o conhecimento, que investe no êxito, motivação, participação e bem-estar dos alunos, promove o valor da escolarização e o sentido dado às aprendizagens. Implica também na atuação eficaz de um corpo docente estável e na presença de estratégias diferenciadas que favoreçam a aprendizagem e o acompanhamento contínuo, de forma a contemplar todos os alunos. (VINHA; MORAIS; MORO, 2017, p. 10)
\end{abstract}

A pesquisadora Díaz-Aguado (2015) explica a importância dos efeitos que a expectativa do professor, no quesito aprendizagem, desperta em seus alunos. Segundo a estudiosa, dependendo da perspectiva que o docente estabelece com seus alunos, é possível alterar todo o processo de ensino-aprendizagem, desde o planejamento de aula até as relações instauradas, a atenção concedida e a própria dinâmica utilizada em sala de aula. Outra questão importante consiste de oportunidades concedidas de protagonismo estudantil. Tais aspectos interferem na qualidade da aprendizagem e na própria motivação do aluno.

Um dos itens levantados no questionário, com considerável discrepância entre as escolas dos grupos 1 e 3, apontando respostas mais positivas nas escolas do Grupo 3, foi: Os professores desta escola explicam de forma clara (com diferença de $13 \%$ entre as escolas dos dois grupos). Esse é um item relevante do clima, na dimensão Aprendizagem, uma vez que demonstra como os alunos avaliam a competência dos professores de sua escola, na sistematização e abordagem do conteúdo que ministram.

Já no item Quando não entendem alguma coisa, podem perguntar para os professores várias vezes, até entenderem, foi igualmente encontrada considerável disparidade percentual (diferença de $8 \%$ ). Entendemos que esse dado fornece a impressão 
de que alunos (especialmente do Grupo 1) não se sentem à vontade para se expressar e muito menos têm coragem de emitir "erros”, o que pode ser um reflexo de como o erro tem sido considerado na escola. Piaget (1973/1998) salienta que, no processo de construção de conhecimento, o erro é tido como um fator de aprendizagem, sendo responsável por um caminho necessário para se chegar a soluções cada vez mais precisas, no percurso da aprendizagem. Para o estudioso, não existe desenvolvimento sem a ocorrência do erro, durante o percurso, portanto, é de grande importância ser enunciado por meio de dúvidas, afirmações, ou seja, durante o desenvolvimento da aula. Em vista disso, a escola precisaria romper com certos paradigmas e valorizar também o processo de construção do conhecimento, evitando a insegurança de alunos questionarem, quando têm dúvidas.

A abordagem desses dois itens mencionados refere-se ao conteúdo da dimensão Aprendizagem, mas envolve também conotação relacional, de sensibilidade ao outro, de observar a realização das atividades, constatando se aprendeu ou não, ou ainda de refletir sobre as reações docentes diante de questionamentos de alunos. Em face disso, retomemos uma outra dimensão que envolve as inter-relações. Trata-se da Dimensão 3, denominada As regras, as sanções e a segurança na escola, cuja definição pauta-se em

[...] como gestores, professores e alunos intervêm nos conflitos interpessoais na escola. Abrange, também, a elaboração, o conteúdo, a legitimidade e a equidade na aplicação das regras e sanções, identificando os tipos de punições geralmente empregadas. Compreende, ainda, a ordem, a justiça, a tranquilidade, a segurança no ambiente escolar e a coerência na aplicação das regras e sanções. (VINHA; MORAIS; MORO, 2017, p. 10)

Para conviver em um espaço por muitas horas diárias, as relações que nele ocorrem precisam ser saudáveis. Piaget (1973/1998) prioriza esse espaço, afirmando que a escola não pode desperdiçar esse ambiente tão rico, pois se trata de uma convivência com pessoas de diferentes origens, com diferentes idades (alunos, professores, funcionários), todos com seus desejos e anseios, partilhando um único espaço, portanto, uma oportunidade ímpar para aprender a viver socialmente e, ainda mais, desenvolver-se moralmente.

O desenvolvimento da moralidade se dá, de acordo com Piaget (1932/1994), por meio de duas tendências morais, a heterônoma e a autônoma, uma das quais tende a superar a outra. Na moral heterônoma, o sujeito age diante das regras, por meio de uma regulação externa, porém, não há consciência, apenas obediência às autoridades, ao passo que a moral autônoma se caracteriza por compreender o princípio da regra. Assim, com diálogo, assembleias, por meio da compreensão da existência das normas, é possível promover o desenvolvimento moral, abandonando práticas heterônomas e educando para a autonomia. 
Dessa maneira, entendemos que as regras e as sanções são importantes para o regulamento da convivência coletiva. Puig (2004) acredita que as regras precisam ser vividas e sentidas pelos alunos, de modo que, diante de casos específicos, o aluno é desafiado a refletir sobre a situação, educando-se em face da significação da existência das normas. Em suas palavras,

[...] aprender normas pelo uso significa estar imerso em um contexto significativo, participar em atividades e práticas, entrar em um fluxo de encontros informativos, e formar vínculos afetivos com seus participantes. (PUIG, 2004, p. 177)

Nessa linha, em favor do desenvolvimento moral do aluno, ao se descumprir uma regra, suas consequências também deveriam ser discutidas. Para Piaget (1930/1996), existem dois tipos de sanções, uma mais relacionada a um desenvolvimento moral autônomo, nomeada sanção por reciprocidade, e outra denominada sanção expiatória, envolvendo punições arbitrárias, a qual não remete ao dano ocasionado.

Dados desta pesquisa demonstraram que a sanção expiatória esteve mais presente em escolas com desempenho abaixo do esperado no Enem. Por exemplo, no item Mudam de lugar os alunos, quando se envolvem em conflitos ou desobedecem às regras, o resultado indicou uma diferença de $10 \%$ para as respostas sempre/muitas vezes, entre as escolas dos grupos 1 e 3, enquanto para o item Colocam os alunos para fora, essa discrepância atingiu 17\%. Isso confirma que escolas onde se privilegiam sanções unilaterais tendem a ter um clima ruim nesse aspecto, além de resultar em desempenho escolar abaixo do que se espera, dada sua situação contextual.

Candian e Resende (2013) ressaltam que um clima normativo mais favorável alcança resultados de desempenho melhores, portanto, os autores recomendam que a gestão se dedique às questões relacionais, em prol de um bom clima escolar e, igualmente, de melhor rendimento acadêmico.

Em virtude da análise dos dados apontados neste estudo, ressalta-se a importância das questões relacionais na escola. Casassus (2002) evidencia, por meio de uma pesquisa envolvendo 14 países latino-americanos, que, dentre 30 variáveis investigadas, um clima favorável à aprendizagem na escola, mais especificamente um clima emocional favorável em sala de aula, foi o aspecto mais importante para que escolas tivessem um desempenho melhor em Linguagem e Matemática. Em acréscimo, a pesquisa revela que essa variável se mostrou mais importante do que o conjunto de todas as outras consideradas.

Com a presente pesquisa, revelou-se que o clima escolar geral apresentou uma discrepância na avaliação entre as escolas dos grupos 1 e 3, sobretudo mediante a avaliação discente e nas dimensões Aprendizagem e Regras, sugerindo que escolas com um clima mais positivo poderiam proporcionar melhores condições na obtenção de um resultado além do esperado no Enem, segundo suas condições contextuais. O mesmo foi observado nas demais dimensões Infraestrutura, Conflitos e Intimidação -, nas quais percebemos que escolas com 
desempenho acima do esperado, perante a perspectiva dos alunos, também avaliaram o clima nessas dimensões mais positivamente.

\section{CONSIDERAÇÕES FINAIS}

Esta pesquisa visava verificar se um clima escolar mais positivo poderia proporcionar um melhor desempenho acadêmico. Os resultados da análise, na perspectiva de alunos, professores e gestores, em comparação com o desempenho sob o efeito escola (controlando o indicador de nível socioeconômico), apontam para a afirmação, ou seja, o clima escolar demonstrou ser um fator protetivo em escolas que obtiveram um desempenho muito acima do esperado, pois houve uma tendência: escolas do Grupo 3 tinham por característica um clima escolar mais positivo do que aquelas do Grupo 1.

Assim, pudemos constatar também que, dos três públicos investigados nas escolas, aquele que se mostrou mais crítico foram os alunos, tanto em escolas com desempenho bem acima do esperado quanto naquelas com desempenho bem abaixo do esperado, pois sua avaliação positiva obteve um percentual menor, comparando-se com a avaliação de professores e gestores. Não diferentemente, foram os alunos que apresentaram uma diferença mais discrepante, comparando-se as escolas dos grupos 1 e 3, seja no clima geral, seja analisando-se as dimensões separadamente. Pode-se presumir que alunos respondem aos questionários de modo mais objetivo, enquanto professores e gestores tenderiam a serem mais cautelosos, levando em consideração sua posição na escola. Esse raciocínio é corroborado pela observação de que os professores se posicionaram de forma mais positiva do que os alunos, e os gestores de modo mais positivo quando comparados aos alunos e professores, independentemente do grupo de escolas.

As dimensões nas quais pudemos observar uma maior influência sobre o desempenho no Enem foram Aprendizagem e Regras; interessantemente, tais temas contemplam questões relacionais, mostrando-se como importantes tanto na convivência sadia e respeitosa quanto na conquista de um desempenho acadêmico acima do esperado, considerando dados contextuais.

O presente artigo não apenas almeja constatar um fenômeno, mas também pretende disseminar a conceituação de clima escolar, assim como promover a importância da avaliação do clima nas escolas. Podemos melhorar um ambiente, a partir de um conhecimento mais profundo - e nada melhor do que uma avaliação para isso. Contudo, somente avaliar não basta: diante do retrato do clima, é necessário olhar com atenção os resultados que mais se destacam e, assim, reforçar as práticas positivas e intervir em aspectos que precisam ser melhorados.

Por fim, foi possível constatar que o clima escolar, além de proporcionar melhor qualidade de vida a todos os membros da comunidade escolar, demonstrou ser um importante elemento que atenua os impactos dos baixos níveis socioeconômicos, revelando-se como um fator protetivo para que alunos se sintam melhor naquele ambiente e conquistem um melhor desempenho acadêmico. 
BERKOWITZ, R.; MOORE, H.; ASTOR. R. A.; BENBENISHTY, R. A research synthesis of the associations between socioeconomic background, inequality, school climate, and academic achievement. Review of Educational Research, v. 20, n. 10, p. 1-45, Nov. 2016.

BRASIL. Ministério da Educação. Instituto Nacional de Estudos e Pesquisas Educacionais Anísio Teixeira. Exame Nacional do Ensino Médio - ENEM. Sobre o ENEM. Brasília, 2016. Disponível em: http://portal.inep.gov. br/web/enem/sobre-o-enem. Acesso em: jul. 2016.

BRASIL. Ministério da Educação. Instituto Nacional de Estudos e Pesquisas Educacionais Anísio Teixeira. Nota Técnica. Indicador Nível Socioeconômico das Escolas. Brasília, 2014. Disponível em: http://download. inep.gov.br/educacao_basica/enem/enem_por_escola/2015/nota_tecnica_indicador_nivel_socioeconomico. pdf. Acesso em: jul. 2016.

BRAULT, M. C. L. Influence du climat scolaire sur les résultats des élèves: effet-établissement ou perception individuelle? 2004. 104 f. (Maitre en Sciences) - Université de Montréal, Montréal, 2004.

CANDIAN, J. F.; REZENDE, W. S. O contexto normativo do clima escolar e o desempenho dos alunos: implicações para o debate sobre gestão escolar. Pesquisa e Debate em Educação, Juiz de Fora, v. 3, n. 2, p. 25-41, 2013.

CANGUÇU, K. L. A. Estudos da associação entre clima escolar e o desempenho médio de alunos do $5^{\circ}$ ano do ensino fundamental. 2015. 161 f. Tese (Doutorado em Educação) - Universidade Federal de Minas Gerais, Belo Horizonte, 2015

CASASSUS, J. A escola e a desigualdade. Brasília: Plano, 2002.

CLARO. J. Calidad en educación y clima escolar: apuntes generales. Estudios Pedagógicos, v. 39, n. 1, p. 347-359, 2013.

DAWSON, B.; TRAPP, R. G. Bioestatística básica e clínica. 3. ed. Rio de Janeiro: McGraw-Hill, 2001.

DÍAZ-AGUADO, M. J. Da violência escolar à cooperação na sala de aula. Americana, SP: Adonis, 2015.

GIL, A. C. Como elaborar projetos de pesquisa. 5. ed. São Paulo: Atlas, 2010.

GIL, A. C. Métodos e técnicas de pesquisa social. 6. ed. São Paulo: Atlas, 2012.

GOTTFREDSON, G. D.; GOTTFREDSON, D. C.; PAYNE, A. A.; GOTTFREDSON, N. C. School climate predictors of school disorder: results from a national study of delinquency prevention in schools. Journal of Research in Crime and Delinquency, v. 42, n. 4, p. 412-444, Nov. 2005.

MA, X.; KLINGER, D. A. Hierarchical linear modelling of student and school effects on academic achievement. Canadian Journal of Education, v. 25, n. 1, p. 41-55, 2000.

MATTINGLY, J. W. A study of relationships of school climate, school culture, teacher efficacy, collective efficacy, teacher job satisfaction and intent to turnover in the context of year-round education calendars. 2007. $362 \mathrm{f}$. Dissertation (Doctor of Philosophy) - University of Louisville, Louisville, 2007.

PERKINS, B. K. Where we learn: the CUBE Survey of Urban School Climate 2006. Alexandria, VA: National School Boards Association, 2006. Disponível em: http://schoolclimatesurvey.com/publications.html. Acesso em: maio 2016.

PERKINS, B. K. Where we teach: the CUBE Survey of Urban School Climate 2007. Alexandria, VA: National School Boards Association, 2007. Disponível em: http://schoolclimatesurvey.com/publications.html. Acesso em: maio 2016.

PERKINS, B. K. What we think: parental perception of urban school climate 2008. Alexandria, VA: National School Boards Association, 2008. Disponível em: http://schoolclimatesurvey.com/publications.html. Acesso em: maio 2016.

PIAGET, J. 0 juízo moral na criança. São Paulo: Summus, 1994. 1ª edição publicada em 1932. 
PIAGET, J. Os procedimentos da educação moral. Tradução de Maria Suzana de Stefano Menin. In: MACEDO, L. Cinco estudos de educação moral. São Paulo: Casa do Psicólogo, 1996. p. 1-36. 1ª edição publicada em 1930.

PIAGET, J. Para onde vai a educação? Rio de Janeiro: José Olympio, 1998. 1ª edição publicada em 1973.

PUIG, J. M. Práticas morais: uma abordagem sociocultural da educação moral. São Paulo: Moderna, 2004.

ROBERTS, J. L. Student's perception of school climate. 2007. 40 f. Thesis (Master of Science) - Rochester Institute of Technology, Rochester, New York, 2007.

SUMMER, M. G. Climate and student performance in Tennessee middle schools. 2006. $139 \mathrm{f}$. Dissertation (Doctor of Education Degree) - University of Tennessee, Knoxville, Tennessee, 2006.

TAYLOR, D. E. The influence of climate on student achievement in elementary schools. 2008. $113 \mathrm{f}$. Dissertation (Doctor of Education) - The Faculty of the Graduate School of Education and Human Development of The George Washington University, Washington, 2008.

THAPA, A.; COHEN, J.; GUFFEY, S.; HIGGINS-D’ALESSANDRO, A. A review of school climate research. Review of Educational Research, v. 83, n. 3, p. 357-385, Sep. 2013.

TRAVITZKI, R. ENEM: limites e possibilidades do Exame Nacional do Ensino Médio enquanto indicador de qualidade escolar. 2013. 322 f. Tese (Doutorado em Educação) - Universidade de São Paulo, São Paulo, 2013.

VINHA, T. P.; MORAIS, A.; MORO, A. (org.). Manual de orientação para a aplicação dos questionários que avaliam o clima escolar. Campinas, SP: FE/Unicamp, 2017.

NOTA: O texto é decorrente da pesquisa de mestrado de Simone Gomes de Melo, sob a orientação da professora Alessandra de Morais. A pesquisa teve o financiamento da Coordenação de Aperfeiçoamento de Pessoal de Nível Superior (Capes).

\section{COMO CITAR ESTE ARTIGO}

MELO, Simone Gomes de; MORAIS, Alessandra de. Clima escolar como fator protetivo ao desempenho em condições socioeconômicas desfavoráveis. Cadernos de Pesquisa, São Paulo, v. 49, n. 172, p. 10-34, abr./jun. 2019. https://doi.org/10.1590/198053145305 
